Article

\title{
Investigating Hydrogen-Based Non-Conventional Storage for PV Power in Eco-Energetic Optimization of a Multi-Energy System
}

\author{
Marialaura Di Somma (D), Martina Caliano, Viviana Cigolotti (D) and Giorgio Graditi * \\ Department of Energy Technologies and Renewable Sources, Italian National Agency for New Technologies, \\ Energy and Sustainable Economic Development, 00123 Rome, Italy; marialaura.disomma@enea.it (M.D.S.); \\ martina.caliano@enea.it (M.C.); viviana.cigolotti@enea.it (V.C.) \\ * Correspondence: giorgio.graditi@enea.it
}

Citation: Di Somma, M.; Caliano, M.; Cigolotti, V.; Graditi, G. Investigating Hydrogen-Based Non-Conventional Storage for PV Power in Eco-Energetic Optimization of a Multi-Energy System. Energies 2021, 14, 8096. https://doi.org/ 10.3390/en14238096

Academic Editor: Antonio D’angola

Received: 5 November 2021

Accepted: 1 December 2021

Published: 3 December 2021

Publisher's Note: MDPI stays neutral with regard to jurisdictional claims in published maps and institutional affiliations.

Copyright: (C) 2021 by the authors. Licensee MDPI, Basel, Switzerland. This article is an open access article distributed under the terms and conditions of the Creative Commons Attribution (CC BY) license (https:// creativecommons.org/licenses/by/ $4.0 /)$.
Abstract: Through the integration of multiple energy carriers with related technologies, multienergy systems (MES) can exploit the synergies coming from their interplay for several benefits towards decarbonization. In such a context, inclusion of Power-to- $X$ technologies in periods of excess renewable electricity supply, removes the need for curtailment of renewable electricity generation. In order to achieve the environmental benefits of MES without neglecting their economic feasibility, the optimal design problem is as crucial as challenging and requires the adoption of a multi-objective approach. This paper extends the results of a previous work, by investigating hydrogen-based nonconventional storage for PV power in the eco-energetic optimization of an MES. The system under study consists of a reversible fuel cell (r-SOC), photovoltaic (PV), electric heat pump, absorption chiller and thermal storage, and allows satisfying the multi-energy needs of a residential end-user. A multi-objective linear problem is established to find the optimal MES configuration including the sizes of the involved technologies with the goal of reducing the total annual cost and the fossil primary energy input. Simulation results are compared with those obtained in previous work with a conventional nanogrid where a combined heat and power (CHP) system with gas-fired internal combustion engine and a battery were present instead of an r-SOC. The optimized configuration of the non-conventional nanogrid allows achieving a maximum primary energy reduction amounting to $66.3 \%$, compared to the conventional nanogrid. In the face of the environmental benefits, the nonconventional nanogrid leads to an increase in total annual costs, which, compared to the conventional nanogrid, is in the range of $41-65 \%$.

Keywords: multi-energy system; multi-objective optimal design; hydrogen carrier; Power-to- $X$; primary energy saving; annual cost; mixed-integer linear programming

\section{Introduction}

The Green Deal has set a new European strategy for transforming the Union into a modern, resource-efficient and competitive economy, in which by 2050 there will no longer be generation of net greenhouse gas emissions and economic growth will no longer be associated with the use of resources. Regarding energy systems, the initiative aims to promote the decarbonization, the active involvement of consumers and citizens' communities, and increasing reliability, adaptability and resilience. The path to achieving the European energy efficiency objectives and targets requires an energy transition stage in which, in line with European strategic agendas (Energy Union Strategy, SET-Plan, Clean Energy Package) and national ones, it is crucial to develop innovative low- $\mathrm{CO}_{2}$ technologies and products for energy in order to ensure the real affirmation of a new model of sustainable energy system. The energy transition requires an increasing use of generation systems based on renewable energy sources (RES), by enhancing the energy systems flexibility, both on the demand and generation side, including storage, in order to provide adequate services for 
the operation of systems based on high levels of non-programmable renewables and on an energy demand which is more sensitive to price signals, and at the same time with the use of electricity as the main energy carrier [1].

Multi-energy systems (MES), based on the integration of multiple energy carriers with related technologies are considered a sustainable energy supply option as compared to traditional fossil-fuel based centralized systems, being able to act supporting EU objectives of decarbonization, penetration of RES and electrification of energy demand [2]. In residential building applications, MES, whereby electricity, gas, heat and cooling can optimally interact with each other, can improve technical, economic and environmental performance of conventional energy systems based on the separate generation of electricity, heat and cooling, in which user energy demands are usually covered by the utility grid, conventional gas-fired boilers and electric chillers [3]. The MES are usually composed of combined heat and power systems (CHPs), RES technologies and electricity and thermal storage units used to cover the users' energy demand [4]. In the context of MES, Power-to-X technologies, such as power-to- $\mathrm{H} 2$ or power-to-heat, represent a rising approach to convert and store excess RES electricity by removing the need for curtailment of renewable electricity generation [5]. Power-to-H2 conversion is among the most promising technologies related to the sector coupling, given the versatility, the storage potential and the energy density of the hydrogen that make it a suitable carrier for integration between the different energy supply chains [6]. Moreover, hydrogen together with electricity can act in support of decarbonization by serving as an alternative storage of RES electricity via electrolyzers, and, at the same time, as a fuel for generating electricity and heat [7-9].

However, this interaction raises important questions on how the hydrogen should be integrated with other energy carriers, while highlighting the importance of the whole energy system optimization. In such a context, the design and operation of an MES is a very complex problem due to the wide range of possible combinations of energy technologies for potential inclusion and their interactions that introduce a large degree of freedom. Moreover, it necessarily requires the adoption of multi-objective optimization approaches that can ensure the reduction in investment, operating and management costs, along with the reduction of environmental impact, while satisfying the users' variable multi-energy demand. At the same time, MES modelling approaches have to be developed to assess the technical and cost implications of integrating hydrogen into the overall energy system, to allow the different energy carriers to operate in a coordinated fashion [10,11].

From a critical analysis of the literature review, it is clear that sector coupling is considered a necessary tool to increase RES penetration in the energy system and therefore to move towards a decentralized sustainable low-carbon system, with the integration of variable, distributed renewable energy sources. The MES can provide the necessary flexibility to match the gap between demand and supply in the presence of high rates of RES. Different energy carriers can be integrated together in the MES framework, such as electricity, gas, heat, cooling and hydrogen. Hydrogen is today considered one of the most remarkable energy carriers to promote the decarbonization of energy systems. The majority of the studies analyzed in the literature review provide results on the technical feasibility of using hydrogen for decarbonizing the energy system as a whole, and positively impact the environmental emissions, by increasing the penetration of RES, as well as on methodologies and tools to control, optimize and design innovative hydrogen-based integrated energy systems.

Increasing shares of RES worldwide have caused strong needs for addressing criticalities related to their variable and non-dispatchable nature [12]. Coupling RES energy to conventional loads may generate difficulties linked to the different temporal profiles of the generation and demand, which create the need for oversizing the RES generators capacity with an increase in the investment costs of the proposed solutions and a negative overproduction of renewable energy [13]. The already well known and discussed concept of decentralized renewable energy systems can be applied to several different configurations depending on the primary energy source/resource (direct solar, wind, hydro, geothermal, 
ocean energy, biomass), energy carrier (heat, chemical forms such as hydrogen, electricity), energy storage (thermal, chemical (e.g., hydrogen, ammonia), electrical (e.g., battery, supercapacitor), mechanical, gravitational) and application. The considered energy carrier may be stored directly into storage systems (e.g., electricity stored in a battery), or transformed into a different form for storage and retrieval (e.g., hydrogen via electrolysis/fuel cell). Hydrogen, the most promising energy carrier, may play a pivotal role towards the decarbonization of energy production [14], since it presents many positive characteristics which are considered fundamental for the transition to sustainable energy scenarios. In particular, it can lead to high-efficiency and zero-emission energy production [15]; it can be used as short-, medium- or long-term storage [16]; it can be used for different applications (e.g., stationary and mobile applications) $[17,18]$ and, utilizing fuel cell technologies, it is the best solution for high efficiency energy production.

Several studies in the literature review deal with the contribution of hydrogen for the decarbonization of decentralized energy systems [19], considering multiple scales and different RES penetration levels. As a common result of all these studies, it is pointed out that to achieve the potential benefits, the integration of production, storage, and enduse solutions is essential in order to minimize costs and maximize efficiency, with the main objective of capitalizing the multi-carrier potential of the MES concept. In particular, the integration of hydrogen technologies in energy systems leads to several benefits at economic, environmental, and technical levels. A case study in [20] presents a CHP plant and hydrogen storage used to integrate different energy carriers (power, gas, and heat) with high production from RES. In this case, it is demonstrated that hydrogen storage plays a fundamental role in decreasing the operational costs of the energy system, while increasing the penetration of energy production from wind. Another case study presented in [21] shows how the integration of hydrogen, electricity and heat can decrease the interruption factor of electricity supply and heat load for an industrial park. Although several interesting results have been discussed in different studies looking at the integration of hydrogen as an energy carrier in MES, recent contributions, such as [22], analyze and discuss that a real transition towards an $\mathrm{H} 2$ economy still faces significant issues linked to the need for technological developments with economic advantages. In particular, some studies, such as [22], highlight the existing barriers towards the transition to a hydrogen economy linked to the high costs of implementation and operation of innovative integrated solutions; these costs are mainly connected to two different aspects: primarily, the costs of hydrogen production, storage, and distribution are still huge, and whether significant opportunities oriented to the decrease in these costs can be facilitated through research and development activities, as well as the increase in market diffusion. On the other hand, a transition to an $\mathrm{H} 2$ economy will necessarily require dedicated hydrogen infrastructures, which are not yet available.

The works analyzed in the literature review aim to demonstrate the effectiveness of hydrogen technologies for sustainability purposes in MES contexts in the presence of multiple energy carriers. However, most of the analyzed works deal with operation aspects, starting from a given configuration of MES. On the other hand, in case of optimal design problems, most works in the literature focus on single economic objectives without a multi-objective approach that is particularly suitable to find good compromise solutions between economic and environmental objectives.

The contribution of this paper is to investigate a hydrogen-based non-conventional storage for RES generation in the eco-energetic design optimization of an MES in the form of a nanogrid, by extending the results of a previous work [23] where a conventional nanogrid was analyzed. The MES under study consists of a reversible fuel cell (r-SOC), a PV system, an electric pump, an absorption chiller and thermal energy storage, and can satisfy the multi-energy demand of a residential end-user. The r-SOC can alternatively operate in solid oxide electrolyzer (SOE) mode and in solid oxide fuel cell (SOFC) mode. In SOE mode, it generates hydrogen from PV power through an electrolyzer and can potentially store hydrogen through a dedicated storage, whereas in SOFC mode, it can operate as 
a CHP by converting hydrogen back to electricity and heat. A multi-objective linear problem is established through a mixed-integer linear programming (MILP) approach, with the aim of finding the optimal MES configuration in terms of types and sizes of the involved technologies by minimizing a weighted sum of the total annual cost and the fossil primary energy input. In the case study, an MES serving a residential end-user is analyzed and simulation results are compared with those obtained with a conventional nanogrid where a CHP with gas-fired internal combustion engine and a conventional battery were present instead of an r-SOC. The optimized configuration of the non-conventional nanogrid allows obtaining a maximum primary energy reduction amounting to $66.3 \%$ as compared to the conventional nanogrid, thanks to the maximization of RES usage. In the face of environmental benefits, the non-conventional nanogrid leads to an increase in total annual costs, which, compared to the conventional nanogrid, is in the range of $41-65 \%$. Although the high investment costs of hydrogen-based technologies that are not mature yet in the market, the results found in this work demonstrate their significant environmental benefits through the maximization of the renewable electricity supply in the nanogrid and the reduction in the fossil energy use.

\section{Description of the Multi-Energy System}

The MES under investigation provides electrical and thermal energy to a residential building. The superstructure of the MES is pre-fixed, including several technologies for generation, conversion and storage to satisfy the electricity, space heating, domestic hot water and cooling demand of the considered building, as shown in Figure 1.

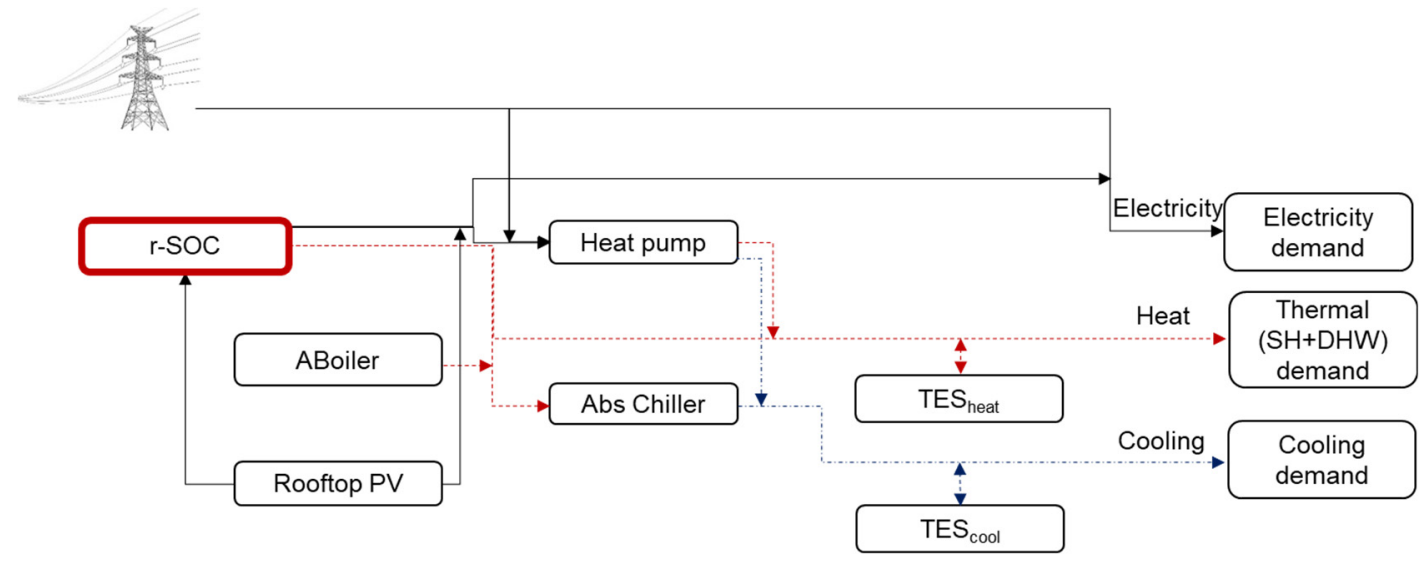

Figure 1. Scheme of the pre-defined superstructure of the MES, energy technologies involved and energy flows among the technologies.

The proposed configuration of the MES aims to characterize a hydrogen-based nonconventional electricity storage for RES generation from the economic and energetic points of view. In detail, the r-SOC can alternatively operate in SOE and in SOFC modes, and the working diagrams used for the implementation of the optimization model are shown in Figure 2 . 


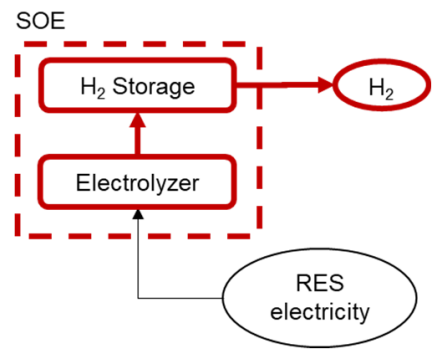

(a)

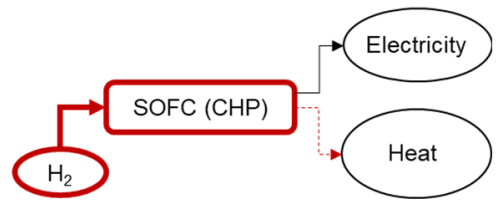

(b)

Figure 2. r-SOC working diagram used for the optimization model: (a) SOE mode; (b) SOFC mode.

According to the superstructure defined in Figure 1, the electricity demand of the user can be covered by the SOFC (CHP), the rooftop PV and the power grid. The thermal energy demand (ambient heating and domestic hot water) of the user can be met by the SOFC (CHP), the gas-fired auxiliary boiler, the heat pump and the thermal storage. Finally, the cooling demand of the user can be covered by the heat pump, the absorption chiller powered by the SOFC $(\mathrm{CHP})$ and the auxiliary boiler, and the thermal energy storage.

\section{Optimal Design Model}

The optimal design model allows finding the best configuration of the MES based on the pre-defined superstructure shown in Figure 1, with the goal of minimizing the total annual cost and the fossil primary energy input, while satisfying the time-varying user demand in terms of electricity, space heating and domestic hot water and space cooling. The decision variables and the objective functions are presented in Sections 3.1 and 3.2, respectively, whereas the problem constraints are presented in Section 3.3. The multiobjective optimization method is discussed in Section 3.4.

\subsection{Decision Variables}

The optimal design problem contains both binary and continuous decision variables. The binary decision variables are the existence and the operation on/off status of the energy technologies, whereas the continuous decision variables include the size of the energy technologies with the corresponding energy amount provided, capacity of thermal storage, with heat rate charging/discharging, amount of hydrogen produced and stored by the $\mathrm{SOE}$, and power taken from the grid.

\subsection{Objective Functions}

The optimal design problem presents two objective functions, namely, economic and energetic. The economic objective function consists of the minimization of the total annual cost, defined as:

$$
C_{\text {Tot }}=C_{\text {Inv }}+C_{O \& M}+C_{f u e l}+C_{\text {grid power }}
$$

where $C_{I n v}$ is the total annualized cost of all energy technologies which depends on the specific capital cost of each technology $j, C_{c, j}$, and the capital recovery factor, $C R F_{j}$ [23]:

$$
C_{\text {Inv }}=\sum_{j} C R F_{j}\left(C_{c, j} S_{j}\right), \quad C R F_{j}=r(1+r)^{N_{j}} /\left[(1+r)^{N_{j}}-1\right]
$$

The O\&M cost in Equation (1) depends on the specific O\&M cost of each technology $j$, $O \mathcal{E} M_{j}$, and the energy rate provided at hour $h r$ and day $d, e_{j, d, h}$ :

$$
C_{O \& M}=\sum_{j} \sum_{d} \sum_{h r} O \& M_{j} e_{j, d, h r} D_{t}
$$


The fuel cost in Equation (1) corresponds to the cost of gas consumed by the auxiliary boiler, that depends on the energy rate provided, $H_{A B, d, h r}$, and efficiency of the boiler, $\eta_{A B}$ :

$$
C_{\text {fuel }}=\sum_{d} \sum_{h r} P_{\text {gas }}\left(H_{A B, d, h r} /\left(\eta_{A B} L H V_{g a s}\right)\right) D_{t}
$$

The grid power cost in Equation (1) depends on the amount of grid power bought at hour $h r$ and day $d$ and the related price $E_{P G, d, h r}$ :

$$
C_{\text {grid power }}=\sum_{d} \sum_{h r} P_{e, h r} E_{P G, d, h r} D_{t}
$$

The energetic objective function consists of the minimization of total annual primary energy input to the MES, formulated as:

$$
P E_{\text {Tot }}=P E_{\text {fuel }}+P E_{\text {grid power }}
$$

where $P E_{f u e l}$ is the primary energy of the input fuel that corresponds to the primary energy of the gas consumed by the auxiliary boiler, whereas $P E_{\text {grid power }}$ is the primary energy of the electricity taken from the grid that depends on the reference electrical efficiency of the power grid which is a parameter dependent on the power generation plants' characteristics in the relevant country:

$$
P E_{\text {grid power }}=\sum_{d} \sum_{h r}\left(E_{P G, d, h r} / \eta_{e, r e f}\right) D_{t}
$$

\subsection{Problem Constraints}

The optimization problem consists of three types of constraints: design, operation and energy balances.

\subsubsection{Design Constraints}

The design constraints for energy technologies ensure that each technology has a size in the range available in the market, and is formulated below [23]:

$$
S_{j}^{\text {min }} x_{j} \leq S_{j} \leq S_{j}^{\max } x_{j}, \forall j
$$

where $x_{j}$ is a binary decision variable representing the selection of the technology in the optimized MES configuration (the variable is equal to 1 if the technology $j$ is selected).

In case of rooftop PV, the design constraint allows limiting the installed area by considering the total available area, that is:

$$
A_{P V} \leq A^{\max }
$$

\subsubsection{Operation Constraints and Modeling of Energy Technologies in the MES}

Operation constraints allow limiting the operation of energy technologies within certain limits that are related to the technologies' characteristics. The common constraint for most energy technologies in the MES is the capacity constraint, formulated below by taking the SOFC as an example:

$$
E_{S O F C}^{\min } x_{S O F C, d, h r} \leq E_{S O F C, d, h r} \leq E_{S O F C}^{\max } x_{S O F C, d, h r}, \forall d, h r
$$

this ensures that the power provided by the SOFC is limited by the capacity and the minimum part load if the technology is on, namely the binary decision variable, $x_{S O F C, d, h r}$ is equal to 1 .

Modeling of the $r$-SOC

As mentioned earlier, the r-SOC in the MES can alternatively operate in SOFC and SOE mode. Under SOFC operation, the r-SOC operates in CHP mode by converting hydrogen 
into electricity and heat. Under SOE operation, the r-SOC operates by generating hydrogen from RES electricity through the electrolyzer powered by the rooftop PV, and storing hydrogen by means of the hydrogen storage. The two operating modes are modeled in the following.

Besides the capacity constraint formulated in Equation (10), the operation constraints for the SOFC in CHP mode are formulated below:

$$
\begin{gathered}
H 2_{S O F C, d, h r}=E_{S O F C, d, h r} /\left(\eta_{e, S O F C} L H V_{H 2}\right), \forall d, h r, \\
H_{S O F C, d, h r}=E_{S O F C, d, h r} \eta_{t h, S O F C} / \eta_{e, S O F C}, \forall d, h r, \\
H_{S O F C, d, h r}=H_{S O F C, d, h r}^{T h}+H_{S O F C, d, h r}^{S C}, \forall d, h r .
\end{gathered}
$$

Equation (11) allows calculating the amount of hydrogen needed by the SOFC to provide the power $E_{S O F C, d, h r}$, and depends on the electrical efficiency of the SOFC, $\eta_{e, S O F C}$. Equation (12) allows calculating the amount of heat rate recovered by the SOFC in CHP mode, whereas Equation (13) is a constraint ensuring that the total amount of this recovered heat is equal to the sum of the parts used to satisfy the building thermal demand and the cooling demand through the absorption chiller.

The operation constraints for the SOE mode are formulated below:

$$
\begin{gathered}
E_{S O E, d, h r}^{r e q}=H 2_{S O E, d, h r} /\left(\eta_{e, S O E} L H V_{H 2}\right), \forall d, h r, \\
E_{S O E}^{m i n} x_{S O E, d, h r} \leq E_{S O E, d, h r}^{r e q} \leq E_{S O E}^{\max } x_{S O E, d, h r}, \forall d, h r, \\
E_{S O E, d, h r}^{r e q}=E_{P V, d, h r}^{E l e c t}, \forall d, h r .
\end{gathered}
$$

Equation (14) allows calculating the power required by the SOE to produce the hydrogen $\mathrm{H} 2_{S O E, h, d r}$ and depends on the electrical efficiency of the electrolyzer in the SOE. Equation (15) constrains this required power between a minimum and a maximum value if the SOE is working (i.e., the binary decision variable, $x_{S O E, d, h r}$, is equal to 1). Equation (16) ensures that the power required by the SOE is equal to the share of power from $\mathrm{PV}$ allocated for usage in the SOE.

Additional operation constraints are needed for the operation of hydrogen storage under the SOE mode, and are formulated below:

$$
\begin{gathered}
0 \leq H 2_{H 2 s t o, d, h r}^{C h} \leq H 2_{H 2 s t o}^{C h, m a x} x_{H 2 s t o}^{C h}, \forall d, h r, \\
0 \leq H 2_{H 2 s t o, d, h r}^{\text {Disch }} \leq H 2_{H 2 s t o}^{\text {Disch,max }} x_{H 2 s t o}^{\text {Disch }}, \forall d, h r, \\
x_{H 2 s t o}^{C h}+x_{H 2 s t o}^{D i s c h} \leq 1, \forall d, h r, \\
H_{H 2 s t o, d, h r}^{s t o}=H_{H 2 s t o, d, h r-1}^{s t o} \eta_{H 2 s t o}+H 2_{H 2 s t o, d, h r}^{C h}-H 2_{H 2 s t o}^{\text {Disch }}, \forall d, h r .
\end{gathered}
$$

where $x_{H 2 s t o}^{C h}$ and $x_{H 2 s t o}^{\text {Disch }}$ are binary decision variables that are equal to 1 if the charging and discharging process is active. Equations (17) and (18) allow the charging and discharging processes, respectively, taking place between a minimum and a maximum value. Equation (19) ensures that the charging and discharging processes do not take place simultaneously, whereas Equation (20) relates the amount of hydrogen stored at time $h r$ of day $d$ with the one stored at previous time $h r-1$ of the same day that depends on the efficiency of the hydrogen storage in the SOE.

Finally, the following constraints allow relating the various components and the two operating modes of the r-SOC.

$$
\begin{gathered}
H 2_{H 2 s t o, d, h r}^{\text {Disch }}=H 2_{S O F C, d, h r}, \forall d, h r \\
H 2_{H 2 s t o, d, h r}^{C h}=H 2_{S O E, d, h r}, \forall d, h r
\end{gathered}
$$


Modeling of the other energy technologies in the MES

In the following, the operation constraints of the other energy technologies in the MES, namely the rooftop PV, the auxiliary boiler, the reversible heat pump, the absorption chiller and the thermal storage are presented. For further details, reference is made to the previous work [23].

$$
\begin{gathered}
E_{P V, d, h r}=A_{P V} \eta_{P V} I_{d, h r}, \forall d, h r \text {, with } E_{P V, d, h r}=E_{P V, d, h r}^{E l e c t}+E_{P V, d, h r}^{L o a d}, \forall d, h r, \\
G_{A B, d, h r}=\frac{H_{A B, d, h r}}{\eta_{t h, A B} L H V_{g a s}}, \forall d, h r \text {, with } H_{A B, d, h r}=H_{A B, d, h r}^{T h}+H_{A B, d, h r}^{S C}, \forall d, h r, \\
E_{H P, d, h r}^{H M}=\frac{H_{H P, d, h r}^{H M}}{C O P_{H P}^{H M}}, \forall d, h r, \\
C_{A C h i l, d, h r}=\left(H_{S O F C, d, h r}^{S C}+H_{A B, d, h r}^{S C}\right) C O P_{A C h i l}, \forall d, h r, \\
H_{T E S, d, h r}^{s t o}=H_{T E S, d, h r-1}^{s t o}\left(1-\varphi_{T E S}\left(D_{t}\right)\right)+\left(H_{T E S, d, h r}^{C h}-H_{T E S, d, h r}^{\text {Disch }}\right) D_{t}, \forall d, h r .
\end{gathered}
$$

\subsubsection{Energy Balance Constraints}

Energy balance constraints ensure that user energy demand is satisfied all times.

Power and thermal energy balances are formulated below.

$$
\begin{gathered}
E_{d, h r}^{d e m}+E_{H P, d, h r}=E_{P V, d, h r}^{L o a d}+E_{S O F C, d, h r}+E_{P G, d, h r}, \forall d, h r, \\
H_{d, h r}^{d e m}=H_{S O F C, d, h r}^{T h}+H_{A B, d, h r}^{T h}+H_{T E S, d, h r}^{D i s c h}-H_{T E S, d, h r}^{C h}, \forall d, h r .
\end{gathered}
$$

The energy balance for cooling can be formulated by following the same approach.

\subsection{Multi-Objective Optimization and Solution Methodology}

As already mentioned, the optimal design problem presents two objective functions, the economic and the energetic ones formulated in Equations (1) and (6), respectively, and both are to be minimized.

In order to solve the multi-objective optimization problem, the weighted sum method is used that allows to minimize a single objective function formulated as a weighted sum of the economic and energetic ones [23]:

$$
\text { Fobj }=c \omega C_{\text {Tot }}+(1-\omega) P E_{T o t},
$$

where $c$ is a constant parameter allowing the same order of magnitude for the two objectives, whereas $\omega$ represents the weight that can vary in the interval [0,1]. For values of $\omega$ equal to 1 , the solution that minimizes $C_{\text {Tot }}$ is identified, whereas for values of $\omega$ equal to 0 , the solution that minimizes $P E_{\text {Tot }}$ is identified. By varying the weight $\omega$ in the interval $[0,1]$, the Pareto frontier can be found.

The problem formulated above in Equations (1)-(30) is linear and involves discrete and continuous variables, and it is solved by branch-and-cut, which is powerful for MILP problems.

\section{Case Study}

In the case study, the final user considered is a single-family house of $200.0 \mathrm{~m}^{2}$ and a net height of $3.0 \mathrm{~m}$, located in the Italian climatic zone E, in the city of Turin.

\subsection{Input Data}

Most input data are the same as those in previous work with a conventional nanogrid [23]. The entire year is divided into four seasons based on the characteristics of the reference climatic zone and the period established by Italian legislation in which the heating systems 
can be switched on. For each season, the hourly load profiles of electricity, space heating and cooling are derived as shown in Figure 3.

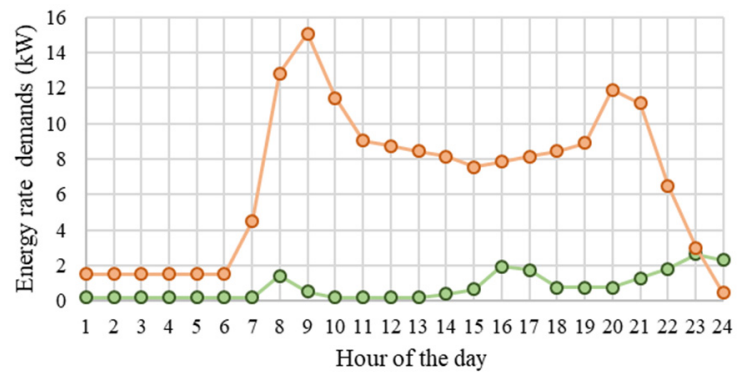

(a)

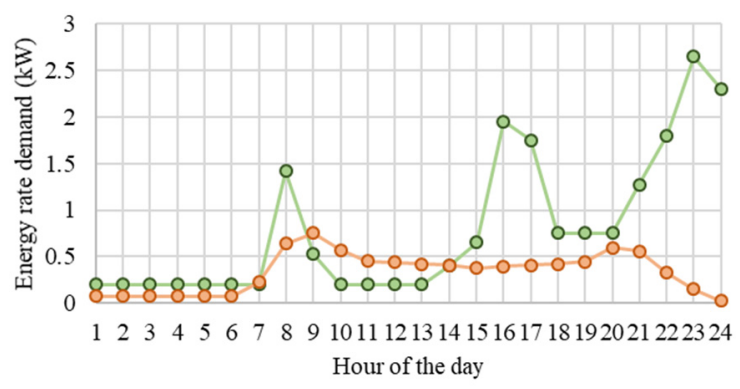

(c)

- - Electrcity demand $\quad-\circ$ - Thermal demand

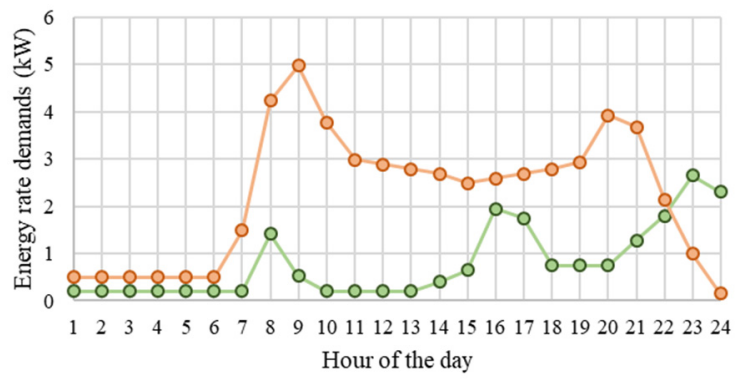

(b)

- - Electrcity demand $\quad-$ - Thermal demand

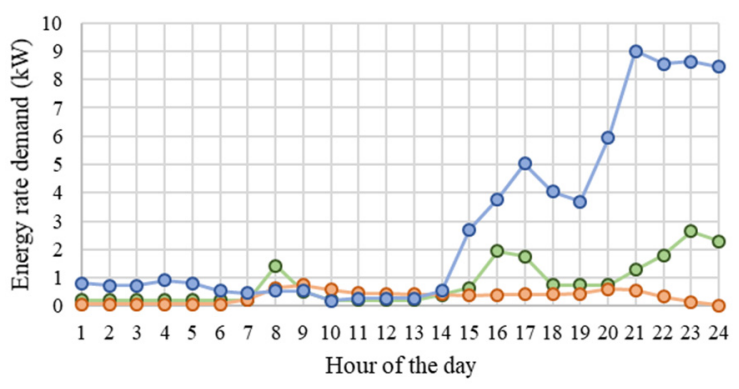

(d)

d) Electrcity demand $-\circ-$ Thermal demand $-\circ-$ Cooling demand

Figure 3. Hourly energy demand profiles for (a) a representative cold season day; (b) a representative cold mid-season day; (c) a representative hot mid-season day; and (d) a representative hot season day.

The optimization is carried out with an hourly time-step and by considering 15 consecutive days for the four seasons of the year.

The inputs to the optimization model are listed below:

- Hourly load profiles for electricity, space heating and domestic hot water and cooling for the residential user. In order to be able to simulate 15 consecutive days, it is assumed that the days of the same season have the same load profiles as the representative day of the season;

- $\quad$ The irradiance profile on an hourly basis on a $35^{\circ}$ tilted surface for the city of Turin [24]. In order to be able to simulate the 15 consecutive days, it is assumed that the days of the same season have the same irradiance profiles as the representative day of the season;

- $\quad$ The prices of energy carriers (electricity and gas), referring to the national energy market. In detail, the unit price of natural gas is assumed as $0.462 € / \mathrm{Nm}^{3}$, whereas the time-of-day electricity price is assumed to vary between 0.123 and $0.152 € / \mathrm{kWh}$. The reference electrical efficiency of the Italian thermoelectric park is set to 0.488 [25].

- The technical-economic characteristics of the technologies that can be implemented as indicated in Table 1. The maximum available area for installation of the rooftop PV arrays is assumed to be $190 \mathrm{~m}^{2}$. The efficiency of the hydrogen storage is assumed to be 1 . The techno-economic information of the r-SOC are based on data collected from market investigation of fuel cell producers. 
Table 1. Techno-economic characteristics of energy technologies in the MES superstructure [26-28].

\begin{tabular}{|c|c|c|c|c|c|c|c|}
\hline $\begin{array}{c}\text { Energy } \\
\text { Technology }\end{array}$ & $\begin{array}{c}\text { Minimum } \\
\text { Size }(k W)\end{array}$ & $\begin{array}{c}\text { Specific } \\
\text { Capital Cost }\end{array}$ & $\begin{array}{l}\text { O\&M Costs } \\
(€ / \mathbf{k W h})\end{array}$ & & $\begin{array}{l}\text { Efficiency } \\
\text { El }\end{array}$ & Th & Lifetime \\
\hline \multirow{2}{*}{ r-SOC } & \multirow{2}{*}{1.0} & \multirow{2}{*}{$16,700 € / \mathrm{kW}$} & \multirow{2}{*}{0.05} & SOFC (CHP) & 0.55 & 0.35 & \multirow{2}{*}{10} \\
\hline & & & & SOE & 0.50 (Electrolyzer) & - & \\
\hline $\begin{array}{l}\text { Auxiliary } \\
\text { boiler }\end{array}$ & 10 & $100 € / \mathrm{kW}$ & 0.015 & & & 0.8 & 15 \\
\hline PV & - & $\begin{array}{c}2000 \\
\text { Eur } / \mathrm{kW}_{\mathrm{p}}\end{array}$ & 0.005 & & 0.14 & & 30 \\
\hline $\begin{array}{l}\text { Reversible } \\
\text { heat pump }\end{array}$ & 5.0 & $460 € / \mathrm{kW}$ & 0.0025 & & & $\begin{array}{l}C O P^{H M}=3.5 \\
C O P^{C M}=3.0\end{array}$ & 20 \\
\hline $\begin{array}{l}\text { Absorption } \\
\text { chiller }\end{array}$ & 1.0 & $510 € / \mathrm{kW}$ & 0.001 & & & 0.8 & 20 \\
\hline TES & - & $20 € / \mathrm{kWh}$ & 0.0014 & & & $\varphi_{\mathrm{TES}}=0.05$ & 20 \\
\hline
\end{tabular}

\subsection{Optimization Results}

The MILP model was implemented in the optimization software IBM ILOG CPLEX Optimization studio V12.10. The optimization problem is composed of 150,940 constraints, 10,086 binary decision variables, 57,608 continuous decision variables, and can be solved in about $420 \mathrm{~h}$ with an average optimization gap lower than $2 \%$, with a PC with $2.60 \mathrm{GHz}$ (2 multi-core processors) Intel(R) Xeon(R) Silver 4214R CPU and 64G RAM.

In the following, in Section 4.2.1, the Pareto frontier of the current case is compared with the one obtained for a conventional multi-energy nanogrid, where a CHP with gasfired internal combustion engine and a battery were present instead of an r-SOC. Optimal design solutions on the various points of the Pareto frontier are discussed in Section 4.2.2, whereas operation strategies of the optimized MES configurations obtained under the economic and environmental optimization are compared in Section 4.2.3.

\subsubsection{Pareto Frontier}

In Figure 4, the Pareto frontier obtained in the current case is compared with the one related to the conventional nanogrid.

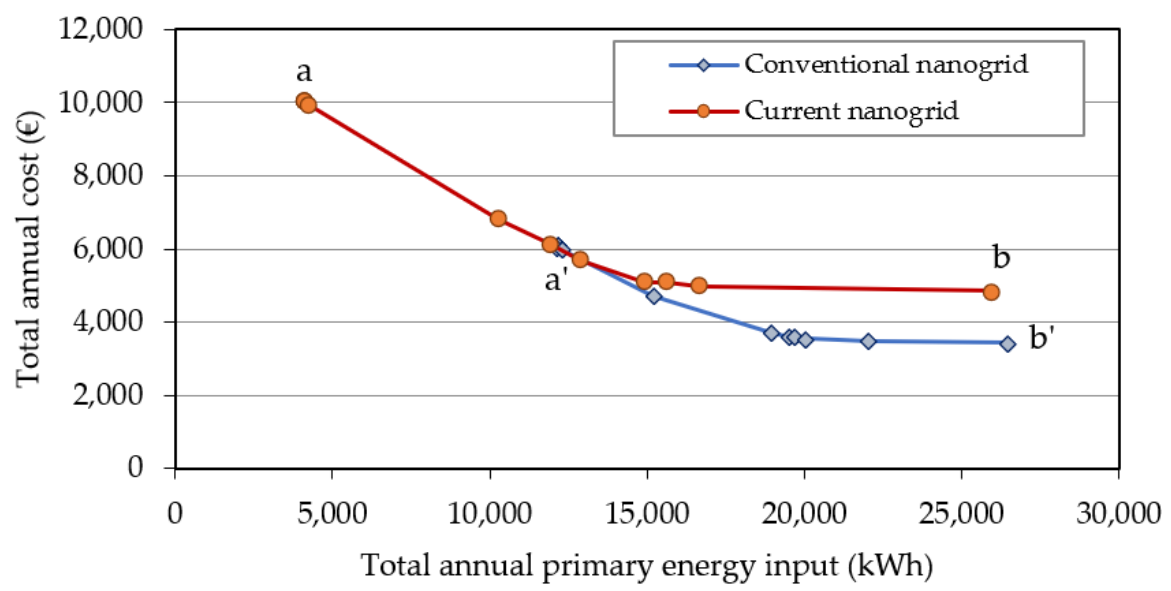

Figure 4. Pareto frontiers of the current and conventional cases.

In details, the points indicated with a and a' related to the configurations of the current and conventional nanogrids, respectively, are obtained with $\omega=0$ or considering only the energetic objective, while the points indicated with $b$ and $b^{\prime}$, related to the configurations of the current and conventional nanogrids, respectively, are obtained with $\omega=1$ or considering only the economic objective. The internal points on the Pareto frontier represent trade- 
off solutions of the economic-energetic optimization problem, which are obtained by subdividing the weight interval into 10 equally-spaced points.

In the current case, under the energetic optimization (point a), the total annual primary energy input is minimum, equal to $4115.2 \mathrm{kWh}$ for a total annual cost of $10,030 €$. Conversely, under the economic objective (point b), the total annual cost is minimum, equal to $4850.8 €$ for a total annual primary energy input equal to $25,990 \mathrm{kWh}$.

From the figure, it can be seen that in the case of energetic optimization, the optimized configuration of the current nanogrid allows achieving a primary energy reduction equal to $66.3 \%$ as compared to the conventional nanogrid. This result highlights the energetic benefits brought by the r-SOC thanks to the hydrogen-based non-conventional storage for PV power. In the case of economic optimization, the optimized configuration of the current nanogrid, beyond the benefits of primary energy savings, brings an increase in total annual costs of $41.6 \%$ as compared to the conventional nanogrid. This result is mainly due to the high specific capital costs of r-SOC technology that makes it noncompetitive yet in the market.

\subsubsection{Optimal Design Solutions}

The optimal design solutions of the MES under study are shown in Table 2 for the various points of the Pareto frontier. It can be noted that for values of $\omega$ varying from 0 to 1 , namely from the energetic optimization to economic one, the size of the r-SOC remains unchanged. A similar trend is found for the size of the auxiliary boiler. Conversely, the size of the installed rooftop PV is maximum under the energetic optimization and for high weights of the energetic objectives, where the total available area of $190 \mathrm{~m}^{2}$ is occupied. For higher weights of the economic objectives, the PV installed area reduces, reaching a minimum under the economic optimization. The size of the reversible heat pump also remains almost unchanged at different values of $\omega$. The absorption chiller is never selected in the optimized MES configurations, whereas it can be noted that the thermal storage capacity for heat reaches the maximum value for higher weight of the energetic objective.

Table 2. Optimized configurations of the MES on the Pareto frontier.

\begin{tabular}{|c|c|c|c|c|c|c|c|c|c|c|c|}
\hline$\omega$ Value & 0 & 0.1 & 0.2 & 0.3 & 0.4 & 0.5 & 0.6 & 0.7 & 0.8 & 0.9 & 1 \\
\hline $\mathrm{r}-\mathrm{SOC}\left(\mathrm{kW}_{\mathrm{e}}\right)$ & 1.0 & 1.0 & 1.0 & 1.0 & 1.0 & 1.0 & 1.0 & 1.0 & 1.0 & 1.0 & 1.0 \\
\hline Auxiliary boiler $\left(\mathrm{kW}_{\mathrm{th}}\right)$ & 10.4 & 10.4 & 10.4 & 10.0 & 10.0 & 0 & 10.0 & 10.0 & 10.0 & 10.0 & 10.0 \\
\hline PV $\left(\mathrm{m}^{2}\right)$ & 190.0 & 190.0 & 190.0 & 182.9 & 129.4 & 124.4 & 96.7 & 62.8 & 59.7 & 51.7 & 21.5 \\
\hline Reversible heat pump $\left(\mathrm{kW}_{\mathrm{th}}\right)$ & 7.3 & 7.3 & 7.3 & 7.5 & 6.2 & 12.8 & 6.7 & 7.1 & 6.9 & 7.4 & 6.7 \\
\hline Absorption chiller $\left(\mathrm{kW}_{\mathrm{th}}\right)$ & 0 & 0 & 0 & 0 & 0 & 0 & 0 & 0 & 0 & 0 & 0 \\
\hline TES (Heat) $\left(\mathrm{kWh}_{\mathrm{th}}\right)$ & 36.1 & 36.1 & 36.1 & 37.3 & 29.2 & 30.5 & 27.6 & 26.6 & 25.6 & 28.5 & 24.7 \\
\hline TES (Cooling) $(\mathrm{kWh}$ th $)$ & 40.1 & 40.1 & 40.1 & 39.9 & 41.4 & 61.2 & 40.6 & 40.3 & 40.5 & 33.0 & 13.7 \\
\hline
\end{tabular}

Figure 5 compares the PV installed area resulting from optimized configurations of the current nanogrid and the conventional one. It can be noted that in the current nanogrid, the installed PV area is larger than in the conventional one, for all weights of the Pareto frontier. This result highlights the benefits related to the hydrogen-based non-conventional storage that allows maximizing the RES usage in the nanogrid, as compared to the current nanogrid where a battery is used as electrical storage. This result is also consistent with those presented in [20], where the impact of power-to-H2 technology and hydrogen storage on penetration rates of renewable power from wind resource was analyzed, and these emerging technologies were found to be effective solutions to maximize the usage of renewable power and avoid curtailments. 


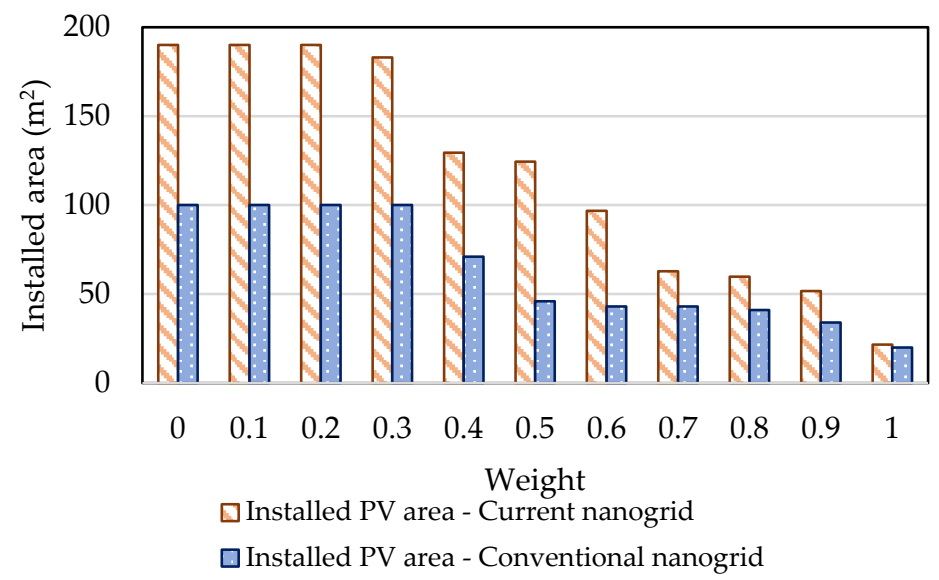

Figure 5. Installed PV area in optimized configurations of the current nanogrid and the conventional one.

4.2.3. Operation Strategies of the Optimized MES Configurations under the Extreme Points on the Pareto Frontier

For each optimized MES configuration, it is possible to analyze the operation strategies for 15 consecutive days for each season. As an illustrative example, the operation strategies obtained for an intermediate day of the winter season are compared below for the economic and energetic optimizations.

Figure 6 shows the power balance in an intermediate day of the winter season obtained for the economic and energetic optimizations. In the case of economic optimization (Figure 6a), the electrical load (sum of the electricity demand and the electricity required by the heat pump) is mainly covered by the grid power, since this operation strategy allows minimizing the total annual costs, and the SOFC is used only in two hours of the day (20 and 21). In the case of energetic optimization (Figure 6b), the contrary occurs, and the electrical load is mainly satisfied by the SOFC, while the power grid is used only to cover the peak loads. In this case, the contribution of the PV system in satisfying the load during the central hours of the day is evident.

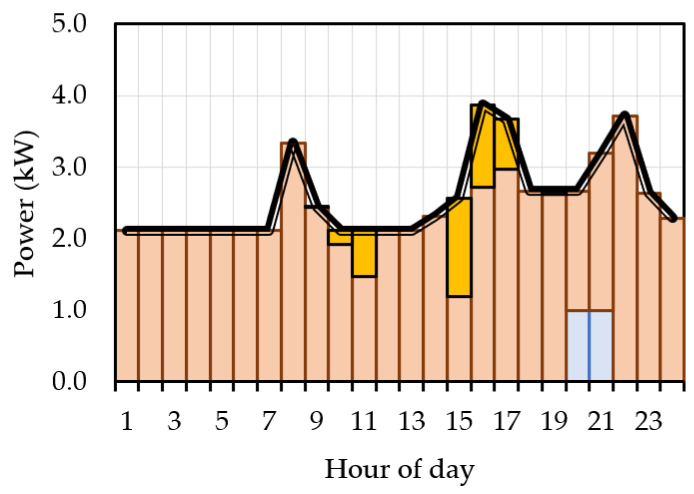

a)

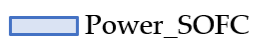

$\square$ Power_PV_load

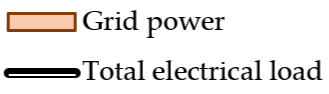

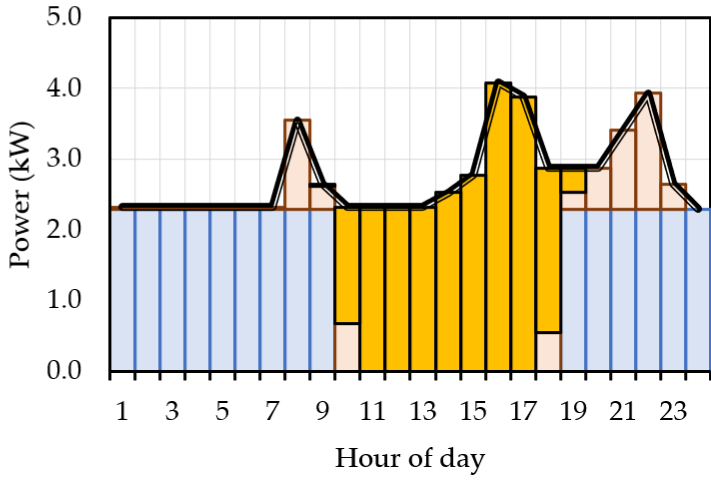

$\square$ Power_SOFC $\square$ Grid power

b)

Figure 6. Power balance in an intermediate day of the winter season for (a) economic optimization and (b) energetic optimization. 
Figure 7 shows the hourly operation strategies for the r-SOC obtained in the case of economic and energetic optimization for an intermediate day of the winter season. In the case of economic optimization (Figure 7a), it can be noted that during the central hours of the day and at hour 18, the power generated by the PV is used for the production of hydrogen and charging of the hydrogen storage, whereas the hydrogen produced and stored is used by the system in SOFC mode at hours 20 and 21. In the case of energetic optimization (Figure $7 \mathrm{~b}$ ), it can be noted that the r-SOC is much more used than in the previous case, not only in terms of working hours but also in terms of power amount produced. The hydrogen stored is used by the system in SOFC mode throughout the day except for the central hours of the day from 11 to 17 . In fact, in this time interval, the electrical power generated by the PV is used for the production of hydrogen and charging of the hydrogen storage.

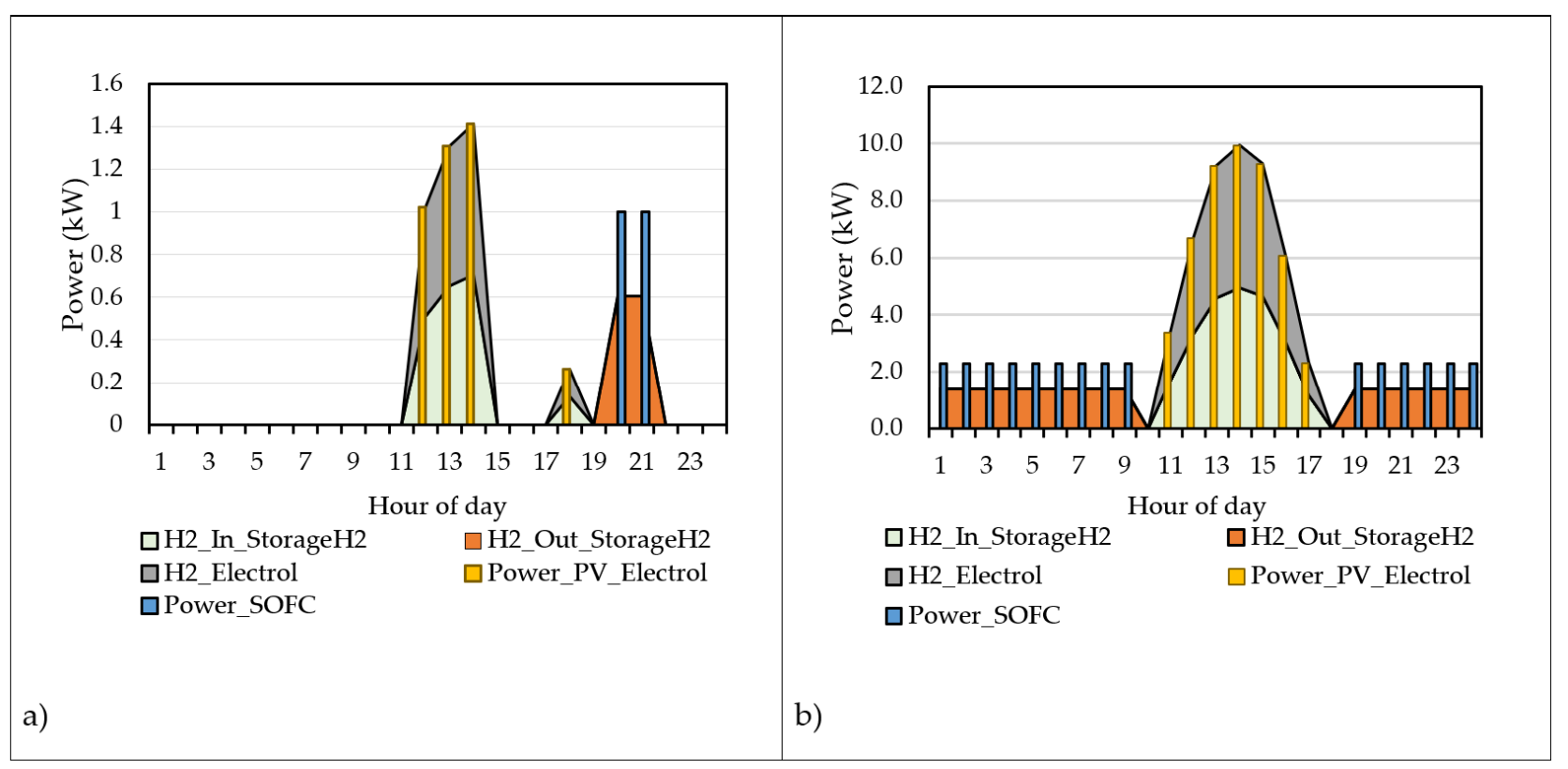

Figure 7. Hourly operation strategies of the r-SOC in the MES configurations in an intermediate day of the winter season for (a) economic optimization and (b) energetic optimization.

Figure 8 shows the thermal energy balance in an intermediate day of the winter season obtained for the economic and energetic optimizations. In the case of the economic optimization (Figure 8a), the thermal load is mainly satisfied by the heat pump and the SOFC in CHP mode and the thermal storage, while the auxiliary gas boiler is used only for covering the peak loads. In the case of energetic optimization, the contribution of the SOFC in CHP mode in the coverage of the thermal load is much more evident. 


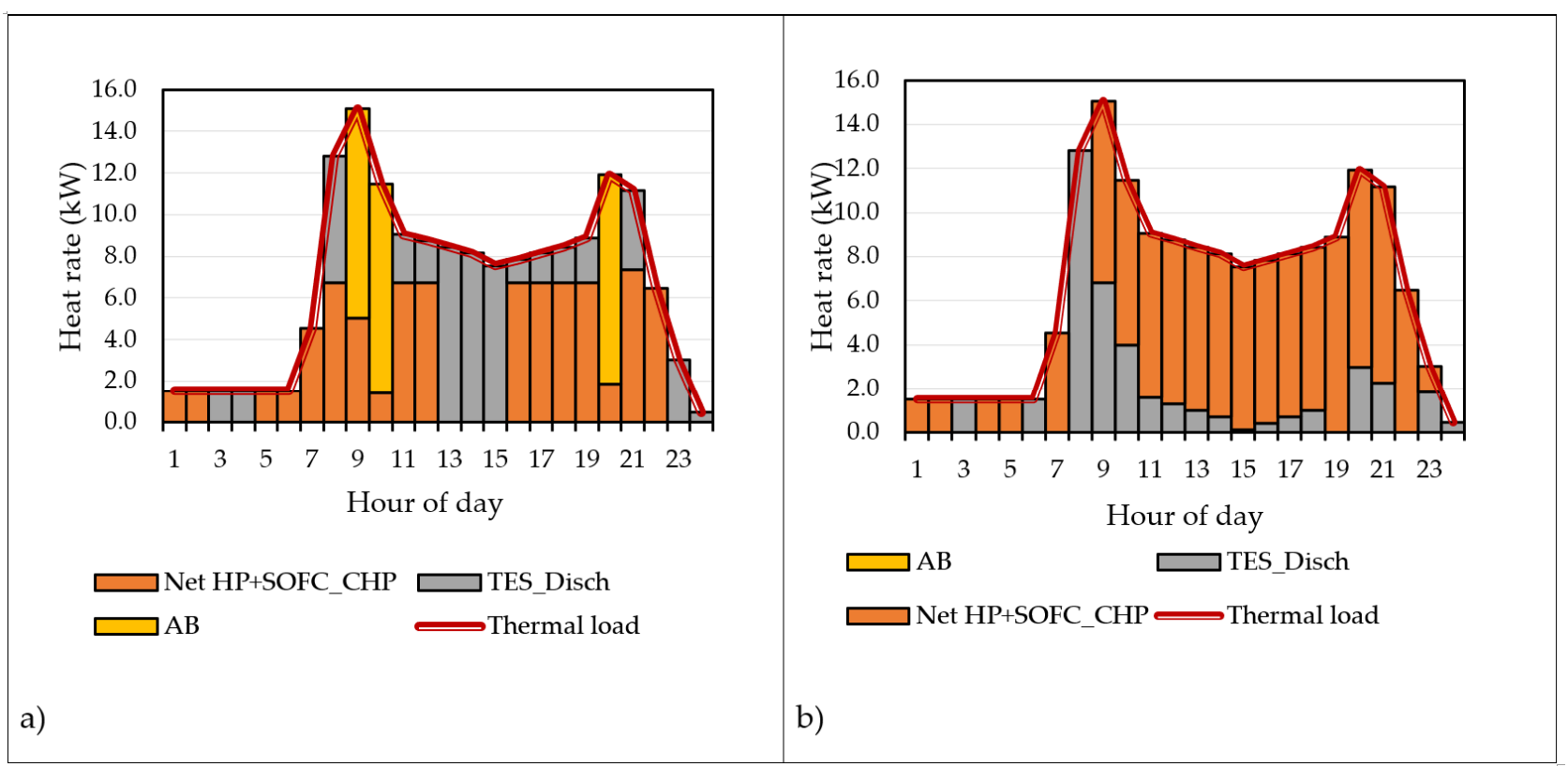

Figure 8. Thermal energy balance in an intermediate day of the winter season for (a) economic optimization and (b) energetic optimization.

\section{Conclusions}

In this paper, a hydrogen-based non-conventional electricity storage for RES generation is investigated under an eco-energetic optimization of an MES for residential applications, by extending the results of a previous work where a conventional nanogrid was analyzed. Based on a pre-fixed MES superstructure, a multi-objective linear problem was formulated through an MILP approach to find the optimal MES configurations in terms of types and sizes of the involved technologies with the aim to reduce a weighted sum of the total annual cost and the fossil primary energy input, while meeting the timevarying multi-energy demand of the user. The Pareto frontier is found by minimizing a weighted sum of the total annual cost and fossil primary input. The problem is solved by branch-and-cut.

The MES under study can include a reversible fuel cell (r-SOC), that can alternatively operate in SOE mode, by generating hydrogen from $\mathrm{PV}$ power by means of an electrolyzer and storing hydrogen by means of $\mathrm{H} 2$ storage, and in SOFC mode, operating as a CHP system by converting hydrogen back to electricity and generating heat. The considered case study is represented by an Italian residential end-user consisting of a single-family house located in the city of Turin. Assigned the hourly load profiles of electricity, ambient heating and domestic hot water and cooling for four representative season days, 15 consecutive days for the four seasons of the year are considered for the optimization process. Simulation results were compared with those obtained in a previous work with a conventional nanogrid where a CHP with gas-fired internal combustion engine, and a conventional battery were present instead of an r-SOC. Results highlight the energetic benefits brought by the r-SOC thanks to the hydrogen-based non-conventional storage for $\mathrm{PV}$ power that allows the r-SOC-based MES to obtain a primary energy reduction equal to $66.3 \%$ as compared to the conventional nanogrid through the maximization of the RES usage. However, beyond the benefits in terms of primary energy savings, in the economic optimization, the optimized configuration of the r-SOC-based MES leads to an increase in total annual costs in the range of $41-65 \%$ compared to the conventional nanogrid, mainly due to the high specific capital costs of the r-SOC technology, which is not yet competitive in the market.

Although the lower convenience of the r-SOC-based MES for economic purposes, the results found in this work show the significant environmental benefits due to the 
integration of hydrogen-based non-conventional electricity storage for RES generation instead of a battery conventional one, by demonstrating the effectiveness of hydrogen technologies for sustainability purposes.

Author Contributions: Conceptualization: M.D.S., M.C., V.C. and G.G.; methodology: M.D.S.; model implementation: M.D.S.; data curation: M.C. and V.C.; writing, review and editing: M.D.S., M.C., V.C. and G.G. All authors have read and agreed to the published version of the manuscript.

Funding: This research was funded by the National Project "ComESto-Community Energy Storage" PON ricerca e innovazione 2014-2020 MIUR-ARS01_01259.

Conflicts of Interest: The authors declare no conflict of interest.

\section{Nomenclature}

\begin{tabular}{|c|c|}
\hline \multicolumn{2}{|c|}{ Decision variables } \\
\hline$A_{P V}$ & installed area of rooftop PV $\left(\mathrm{m}^{2}\right)$ \\
\hline$C$ & $\operatorname{cost}(€)$ \\
\hline$E_{d, h r}$ & power $(\mathrm{kW})$ \\
\hline$e_{j, d, h r}$ & technology's generation level $(\mathrm{kW})$ \\
\hline Fobj & objective function \\
\hline$G_{d, h r}$ & volumetric flow rate of natural gas $\left(\mathrm{Nm}^{3} / \mathrm{h}\right)$ \\
\hline$H 2_{d, h r}$ & volumetric flow rate of hydrogen $\left(\mathrm{m}^{3} / \mathrm{h}\right)$ \\
\hline$H_{d, h r}$ & heat rate $(\mathrm{kW})$ \\
\hline$P E$ & primary energy input $(\mathrm{kWh})$ \\
\hline$S$ & designed size $(\mathrm{kW})-(\mathrm{kWh})$ \\
\hline$x$ & binary decision variable \\
\hline \multicolumn{2}{|c|}{ Parameters } \\
\hline$A^{\max }$ & available area for rooftop PV $\left(\mathrm{m}^{2}\right)$ \\
\hline$c$ & constant in Equation $(30)(\mathrm{kWh} / €)$ \\
\hline$C_{c}$ & specific capital cost $(€ / \mathrm{kW})-(€ / \mathrm{kWh})-\left(€ / \mathrm{m}^{2}\right)$ \\
\hline COP & coefficient of performance \\
\hline$C R F$ & capital recovery factor \\
\hline$D_{t}$ & time interval length $(\mathrm{h})$ \\
\hline$E^{\max }$ & capacity of the technology $(\mathrm{kW})$ \\
\hline$E^{\min }$ & mimimum part load of the technology $(\mathrm{kW})$ \\
\hline$I_{d, h r}$ & total solar irradiance $\left(\mathrm{kW} / \mathrm{m}^{2}\right)$ \\
\hline$L H V_{g a s}$ & lower heat value of natural gas $\left(\mathrm{kWh} / \mathrm{Nm}^{3}\right)$ \\
\hline$L H V_{H 2}$ & lower heat value of hydrogen $\left(\mathrm{kWh} / \mathrm{m}^{3}\right)$ \\
\hline$N$ & lifetime (years) \\
\hline$O M$ & specific O\&M cost $(€ / \mathrm{kWh})$ \\
\hline$P_{e, h r}$ & electricity price $(€ / \mathrm{kWh})$ \\
\hline$P_{g a s}$ & natural gas price $\left(€ / \mathrm{Nm}^{3}\right)$ \\
\hline$r^{\circ}$ & interest rate \\
\hline$S^{\max }$ & maximum size available in the market $(\mathrm{kW})$ \\
\hline$S^{\min }$ & minimum size available in the market $(\mathrm{kW})$ \\
\hline$\eta$ & efficiency \\
\hline$\eta_{e, r e f}$ & reference electrical efficiency of the power grid \\
\hline$\varphi_{T E S}$ & storage loss fraction \\
\hline$\omega$ & weight in Equation (30) \\
\hline \multicolumn{2}{|c|}{ Superscript/Subscripts } \\
\hline$A B$ & auxiliary boiler \\
\hline AChil & absorption chiller \\
\hline$C h$ & charging \\
\hline$d$ & day \\
\hline dem & demand \\
\hline Disch & discharging \\
\hline Elect & electrolyzer \\
\hline fuel & fuel \\
\hline
\end{tabular}




$\begin{array}{ll}\text { grid power } & \text { grid power } \\ \text { H2 } & \text { hydrogen } \\ \text { HM } & \text { heating mode } \\ \text { hr } & \text { hour } \\ \text { INV } & \text { investment } \\ j & \text { index of energy technology } \\ \text { max } & \text { maximum } \\ \text { min } & \text { minimum } \\ \text { OEM } & \text { operation and maintenance } \\ \text { PG } & \text { power grid } \\ \text { PV } & \text { photovoltaic } \\ \text { req } & \text { required } \\ \text { SC } & \text { space cooling } \\ \text { SOE } & \text { SOE mode } \\ \text { SOFC } & \text { SOFC mode } \\ \text { Sto } & \text { stored } \\ \text { TES } & \text { thermal energy storage } \\ \text { Th } & \text { thermal } \\ \text { TOT } & \text { total } \\ \text { Acronyms } & \\ \text { CHP } & \text { micro combined heat and power } \\ \text { MES } & \text { multi energy system } \\ \text { MILP } & \text { mixed-integer linear programming } \\ \text { OEM } & \text { operation and maintenance } \\ \text { PV } & \text { photovoltaic } \\ r-S O C & \text { reversible solid oxide fuel cell } \\ \text { SOE } & \text { solid oxide electrolyzer } \\ \text { SOFC } & \text { solid oxide fuel cell } \\ & \end{array}$

\section{References}

1. Mladenov, V.; Chobanov, V.; Georgiev, A. Impact of Renewable Energy Sources on Power System Flexibility Requirements. Energies 2021, 14, 2813. [CrossRef]

2. Chicco, G.; Di Somma, M.; Graditi, G. Overview of distributed energy resources in the context of local integrated energy systems. In Distributed Energy Resources in Local Integrated Energy System; Di Somma, M., Graditi, G., Eds.; Elsevier: Amsterdam, The Netherlands, 2021; pp. 1-29.

3. Vahid-Ghavidel, M.; Javadi, M.S.; Gough, M.; Santos, S.F.; Shafie-Khah, M.; Catalão, J.P. Demand response programs in multienergy systems: A review. Energies 2020, 13, 4332. [CrossRef]

4. Roberto, R.; De Iulio, R.; Di Somma, M.; Graditi, G.; Guidi, G. A multi-objective optimization analysis to assess the potential economic and environmental benefits of distributed storage in district heating networks: A case study. Int. J. Sustain. Energy Plan Manag. 2019, 20, 5-20. [CrossRef]

5. Eveloy, V.; Romeo, L.M.; Parra, D.; Qadrdan, M. Editorial: Advances in Power-to-X: Processes, Systems, and Deployment; Frontiers Media SA: Lausanne, Switzerland, 2021. [CrossRef]

6. Cigolotti, V.; Genovese, M.; Fragiacomo, P. Comprehensive review on fuel cell technology for stationary applications as sustainable and efficient poly-generation energy systems. Energies 2021, 14, 4963. [CrossRef]

7. Sanders, D.; Hart, A.; Ravishankar, M.; Brunert, J.; Strbac, G.; Aunedi, M. An Analysis of Electricity System Flexibility for Great Britain; Carbon Trust/Imperial College: London, UK, 2016.

8. Strbac, G.; Pudjianto, D.; Sansom, R.; Djapic, P.; Ameli, H.; Shah, N.; Brandon, N.; Hawkes, A.; Qadrdan, M. Analysis of Alternative UK Heat Decerbonisation Pathways; Imperial College London: London, UK, 2018.

9. Fu, P.; Pudjianto, D.; Zhang, X.; Strbac, G. Integration of Hydrogen into Multi-Energy Systems Optimisation. Energies 2020, 13, 1606. [CrossRef]

10. Mancarella, P. MES (multi-energy systems): An overview of concepts and evaluation models. Energy 2014, 65, 1-17. [CrossRef]

11. Bottecchia, L.; Lubello, P.; Zambelli, P.; Carcasci, C.; Kranzl, L. The Potential of Simulating Energy Systems: The Multi Energy Systems Simulator Model. Energies 2021, 14, 5724. [CrossRef]

12. IRENA. International Renewable Energy Agency Global Renewables Outlook: Energy Transformation 2050; IRENA: Abu Dhabi, United Arab Emirates, 2020.

13. Bailera, M.; Peña, B.; Lisbona, P.; Romeo, L.M. Decision-making methodology for managing photovoltaic surplus electricity through Power to Gas: Combined heat and power in urban buildings. Appl. Energy 2018, 228, 1032-1045. [CrossRef]

14. Thomas, J.M.; Edwards, P.P.; Dobson, P.J.; Owen, G.P. Decarbonising energy: The developing international activity in hydrogen technologies and fuel cells. J. Energy Chem. 2020, 51, 405-415. [CrossRef] [PubMed] 
15. Gabrielli, P.; Gazzani, M.; Mazzotti, M. Electrochemical conversion technologies for optimal design of decentralized multi-energy systems: Modeling framework and technology assessment. Appl. Energy 2018, 221, 557-575. [CrossRef]

16. Davis, S.J.; Lewis, N.S.; Shaner, M.; Aggarwal, S.; Arent, D.; Azevedo, I.L.; Benson, S.M.; Bradley, T.; Brouwer, J.; Chiang, Y.M.; et al. Net-zero emissions energy systems. Science 2018, 360, 6396. [CrossRef] [PubMed]

17. Coleman, D.; Kopp, M.; Wagner, T.; Scheppat, B. The value chain of green hydrogen for fuel cell buses-A case study for the Rhine-Main area in Germany. Int. J. Hydrogen Energy 2020, 45, 5122-5133. [CrossRef]

18. Shulga, R.N.; Putilova, I.V. Multi-agent direct current systems using renewable energy sources and hydrogen fuel cells. Int. J. Hydrogen Energy 2020, 45, 6982-6993. [CrossRef]

19. Fonseca, J.D.; Camargo, M.; Commenge, J.M.; Falk, L.; Gil, I.D. Trends in design of distributed energy systems using hydrogen as energy vector: A systematic literature review. Int. J. Hydrogen Energy 2019, 24, 9486-9504. [CrossRef]

20. Heris, M.N.; Mirzaei, M.A.; Asadi, S.; Mohammadi-Ivatloo, B.; Zare, K.; Jebelli, H.; Marzband, M. Evaluation of hydrogen storage technology in risk-constrained stochastic scheduling of multi-carrier energy systems considering power, gas and heating network constraints. Int. J. Hydrogen Energy 2020, 45, 30129-30141. [CrossRef]

21. Liu, J.; Cao, X.; Xu, Z.; Guan, X.; Dong, X.; Wang, C. Resilient operation of multi-energy industrial park based on integrated hydrogen-electricity-heat microgrids. Int. J. Hydrogen Energy 2020, 46, 28855-28869. [CrossRef]

22. Nazir, H.; Muthuswamy, N.; Louis, C.; Jose, S.; Prakash, J.; Buan, M.E.; Flox, C.; Chavan, S.; Shi, X.; Kauranen, P.; et al. Is the H2 economy realizable in the foreseeable future? Part III: H2 usage technologies, applications, and challenges and opportunities. Int. J. Hydrogen Energy 2020, 45, 28217-28239. [CrossRef] [PubMed]

23. Di Somma, M.; Caliano, M.; Graditi, G.; Pinnarelli, A.; Menniti, D.; Sorrentino, N.; Barone, G. Designing of cost-effective and low-carbon multi-energy nanogrids for residential applications. Inventions 2020, 5, 7. [CrossRef]

24. ASHRAE. ASHRAE International Weather files for Energy Calculations (IWEC Weather Files); Users Manual and CD-ROM; American Society of Heating, Refrigerating and Air-Conditioning Engineers: Atlanta, GA, USA, 2001.

25. National System for Environmental Protection (ISPRA), R280/2018. Fattori di Emissione Atmosferica di Gas a Effetto Serra e Altri Gas Nel Settore Elettrico. 2018; (In Italian). Available online: http:/ / www.isprambiente.gov.it/files2018/pubblicazioni/ rapporti/R_280_18_Emissioni_Settore_Elettrico.pdf (accessed on 11 February 2021).

26. Di Somma, M.; Yan, B.; Bianco, N.; Graditi, G.; Luh, P.B.; Mongibello, L.; Naso, V. Design optimization of a distributed energy system through cost and exergy assessments. Energy Procedia 2017, 105, 2451-2459. [CrossRef]

27. Darrow, K.; Tidball, R.; Wang, J.; Hampson, A. Catalog of CHP Technologies; 2015. Available online: https: / /www.epa.gov / sites / production/files/2015-07/documents / catalog_of_chp_technologies.pdf (accessed on 11 February 2021).

28. Technology Data for Energy Plants. Energinet.dk; 2012. Available online: https://www.energinet.dk/SiteCollectionDocuments/ Danske\%20dokumenter/Forskning/Technology_data_for_energy_plants.pdf (accessed on 12 February 2021). 